\title{
Short Outcome Evaluation of Laparoscopic Ventral Hernia Repair \\ Ahmed Saleh Mostafa Baghdady, Hussein Ali Mostafa,
}

Abd El Aal Ali Salem, Hassan Ahmed Abdullah, Mohamed Rabie Saad

Department of General surgery, Faculty of Medicine, Aswan University, Egypt

*Corresponding author: Ahmed Saleh Mostafa Baghdady, Mobile: (+20) 01113726222, E-Mail: asb1010@gmail.com

\begin{abstract}
Background: Ventral hernia is defined as primary anterior abdominal wall and incision hernia not including the groin. There are number of risk factors that lead to hernia to occur; like wound infection, morbid obesity, immunosuppression, previous operations, prostatism, and surgery for aneurysmal disease. Hernia defect can form within first 5 years of surgery but can occur late as well.

Objective: To evaluate the short-term outcome of laparoscopic ventral hernia repair as regard feasibility and safety, operative time and types of hernias.

Patients and methods: This study is a prospective nonrandomized study. It included forty out of sixty consecutive patients admitted at the Department of General Surgery, Aswan University, Aswan Egypt, with diagnosis of ventral and or incisional hernia in the period from July 2016 to December 2019.

Results: This study included 22 male and 18 female patients. 11 male patients had incisional hernia and 11 patients with ventral hernia. Types of hernias: Twenty-one cases had virgin abdomen with no previous surgeries while 19 cases had previous surgery done before; described as follows: midline laparotomy scar (11), caesarian section scar (5), port site scar (2) and appendectomy scar (1). Operative time: In first 20 operated cases the mean operative time was 120 min while in the last 20 cases with increasing learning curve the operative time starts to reduce markedly, and the mean time became $70 \mathrm{~min}$.

Conclusion: Laparoscopic ventral hernia repair is an appropriate, safe and feasible approach for ventral hernia repair with short operative time.
\end{abstract}

Keywords: Laparoscopic, Ventral hernia.

\section{INTRODUCTION}

Ventral and incisional hernia repair is one of the most common operations performed in everyday clinical practice. Incisional hernia is a common longterm complication of abdominal surgery and is estimated to occur in 11-20\% of laparotomy incisions. Almost 50\% of incisional hernias develop within the first 2 years after the primary surgery, and $74 \%$ develop after 3 years ${ }^{(\mathbf{1})}$.

The recurrence rate of incisional hernia after primary suture repair is more than $50 \%$ and has been reduced to $10-23 \%$ after the introduction of prosthetic materials (meshes) in hernia repair. However, open hernia repair can be major operation with considerable morbidity caused by infectious complications. An increasing interest in laparoscopic surgery and the availability of new materials have encouraged the adoption of laparoscopic techniques in ventral hernia repair ${ }^{(2,3)}$.

Leblanc and Booth ${ }^{(4)}$ described the first laparoscopic ventral hernia repair (LVHR) in 1991. It is based on the same physical and surgical principles as the open underlay procedure described by Stoppa ${ }^{(5)}$, Rives et al. ${ }^{\left({ }^{(6)}\right.}$ and Wantz ${ }^{(7)}$. LVHR is now being used with increasing frequency, even for the management of complex incisional hernias. Most reports on this topic have supported minimal postoperative morbidity, a shorter convalescence period, and an acceptable recurrence rate ${ }^{(\mathbf{8})}$.
Ventral hernias are associated with reduced daily activities and high socioeconomic costs for its operations. The use of mesh has reduced surgical failure. Before the introduction of prosthesis, recurrence rate exceeded $50 \%$ of cases. The introduction of laparoscopic repair is an increasingly used alternative technique to open repair ${ }^{(9)}$.

The aim behind this study was to evaluate the short-term outcome of laparoscopic ventral hernia repair as regard feasibility and safety, operative time and types of hernias.

\section{PATIENTS AND METHODS}

This study a prospective nonrandomized study. It included forty out of sixty consecutive patients admitted at the Department of General Surgery, Aswan University, Aswan Egypt, with diagnosis of ventral and or incisional hernia in the period from July 2016 to December 2019 who fulfilled the inclusion criteria were enrolled in the study sample.

Inclusion criteria: All patients with ventral abdominal hernia (epigastric, umbilical, paraumbilical), patients with incisional hernia (not complicated or recurrent) with defect size less than $10 \mathrm{~cm}$, and patients fit for general anesthesia ASA I, II, and III.

Exclusion criteria: Patients unfit for general anesthesia ASA IV and V, patients with severe 
coagulopathy, complicated hernia (obstructed or strangulated), huge hernia more than $10 \mathrm{~cm}$ defect size with loss of abdominal domain, and unwilling or refusal of the patient to do laparoscopic repair.

\section{Ethical consent:}

All patients admitted with a diagnosis of ventral hernia and or incisional hernia who fulfilled the criteria were given the option of open or laparoscopic repair after explanation of both techniques to them as regards advantages, disadvantages. Only those who accept the laparoscopic approach were included in this study.

An approval of the study was obtained from Aswan University Academic and Ethical Committee. Every patient signed an informed written consent for acceptance of the operation.

\section{Methods:}

\section{A. Perioperative assessment:}

All patients were subjected to through history taking and clinical and physical examination; with emphasis on age, sex, comorbidities (diabetes mellitus (DM), hypertension, obesity, chronic obstructive lung disease (COPD)), type of hernia, size of the defect, history of previous operation, history of complications and recurrence.

\section{B. Laboratory and imaging investigations:}

- Complete blood picture, blood sugar, urea, coagulation profile, liver function tests done for all patients.

- ECG and chest X-ray for those patients above the age of forty years.

- Ultrasound for all patients but CT scan for selected patients with suspected complicated hernia with multiple defects and suspected other intraabdominal pathology.

- Optimization of the general condition of the patients as much as possible done for the patients before surgery as this is elective operation, e.g. weight reduction and control of DM, hypertension, coagulation profile abnormalities.

- Venous thromboembolism (VTE) assessment and prophylaxis against deep venous thrombosis (DVT) was performed specially in risky patients. Regarding of American society of Hematology 2018 guidelines for prophylaxis of DVT, we used mechanical methods as elastic stocking or intermittent pneumatic pressure device in minor risk patients and pharmacological agent as low molecular weight heparin or both in moderate risk patients.

C. Single dose of $1^{\text {st }}$ generation Cephalosporin (cefazolin $1 \mathrm{gm}$ ) given to all patients at the time of induction of anesthesia or within 60 minutes before the procedure.

\section{Operative details:}

All patients received general endotracheal anesthesia.

\section{Abdominal axis and trocar placement:}

Induction of pneumoperitoneum using Veress needle $2 \mathrm{~cm}$ below the left costal margin in the mid clavicular line (palmer's point), open hasson technique or optical trocar for primary port placement. Secondary port placement performed under direct vision and placed as lateral from the hernia defect as possible. Three to four ports usually needed. One of them $10 \mathrm{ml}$ for mesh insertion.

We started with exploration of the abdomen, then focusing on the hernia site. Adhesiolysis done with sharp and blunt dissection avoiding the use electrocautery as much as possible or use of bipolar cautery or harmonic as it is safe. Reduction of the contents of the hernial sac with repeated inspection of bowel after adhesiolysis to look for enterotomies (inadvertent injury to the bowel loops). After reduction of the contents we measured the size of the defect both externally and internally with focusing on the internal measurement as this represent the actual size of the defect specially if there are multiple defects.

We measured the defect by inserting a long needle from outside the abdomen to edges of defect inside the abdomen and measure the length or the width from outside. Repair of the defect done by using the intraperitoneal Gortex Dual Mesh spread to cover the defect and five $\mathrm{cm}$ all around from the edge. Fixation of the mesh to the abdominal wall done by using tacks as it is rapid and less time consuming with transfacial 4 corners suture occasionally.

Primary closure of the facial defect by using suture only done if the defect size is less than $5 \mathrm{~cm}$. After ensure good hemostasis and proper fixation of the mesh and no evidence of bowel injury, the $\mathrm{CO}_{2}$ gas was released from the abdomen and the port site closed using proline $3 / 0$ or skin stippling. 

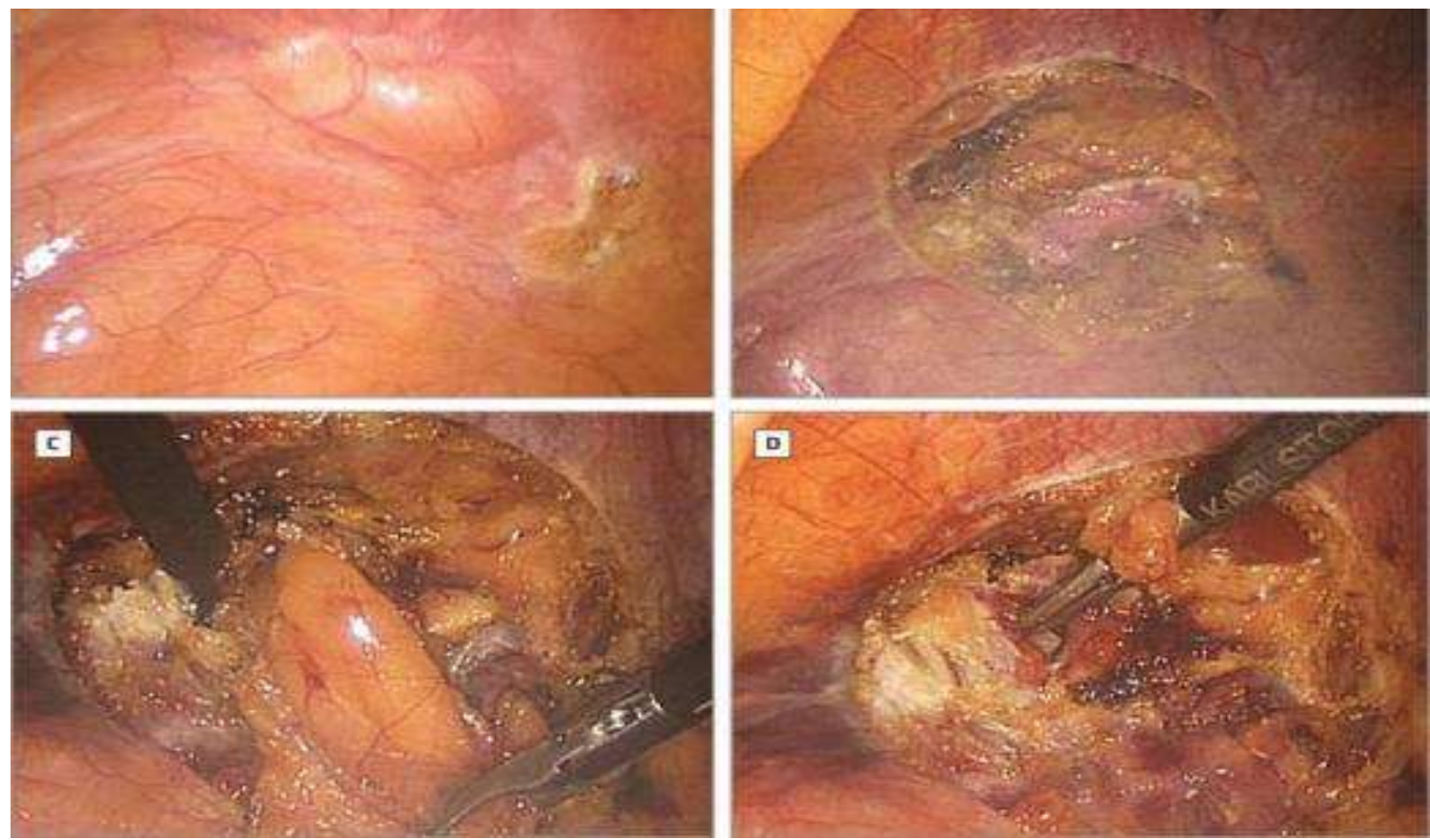

Fig. (1): Identification of primary ventral hernia (A), excision of hernia sac (B), excision of preperitoneal fat (C), and complete exposure of the hernia fascial edges (D).

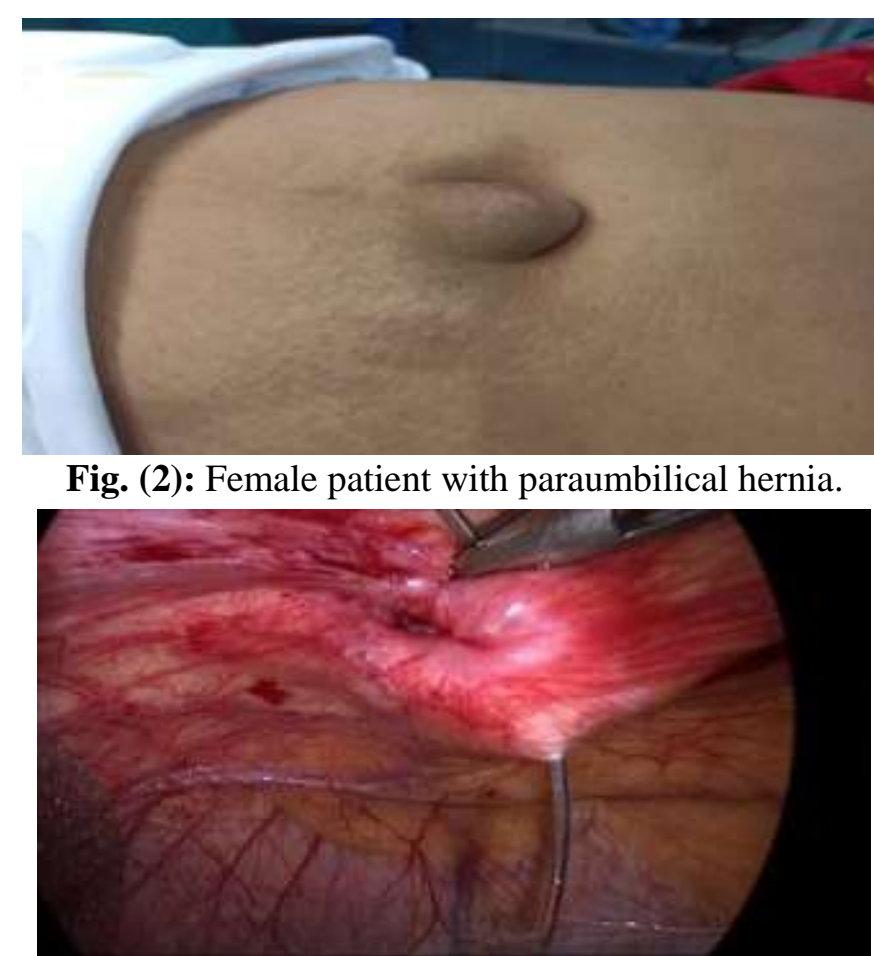

Fig. (3): Closure of the hernia defect.

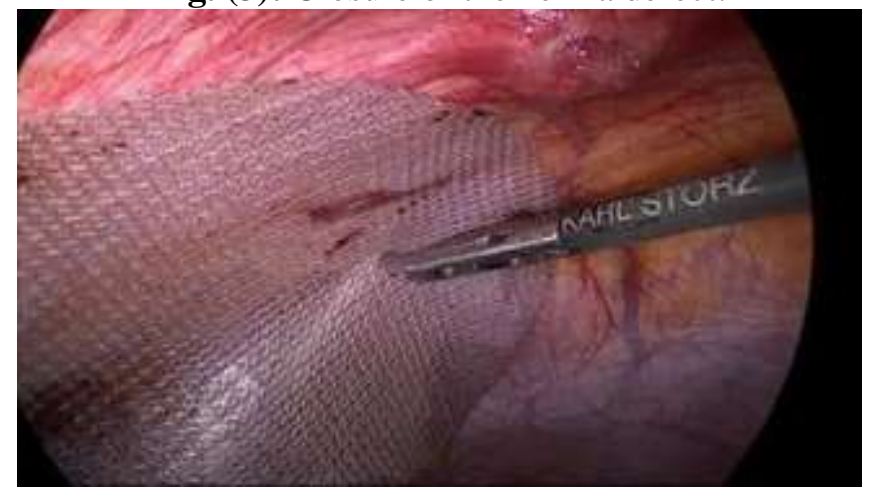

Fig. (5): Spreading of the mesh.

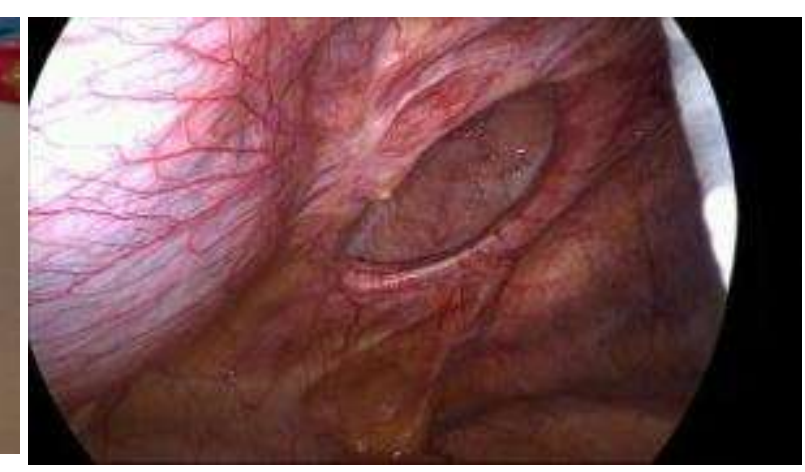

Fig. (3): Laparoscopic view of hernia defect.

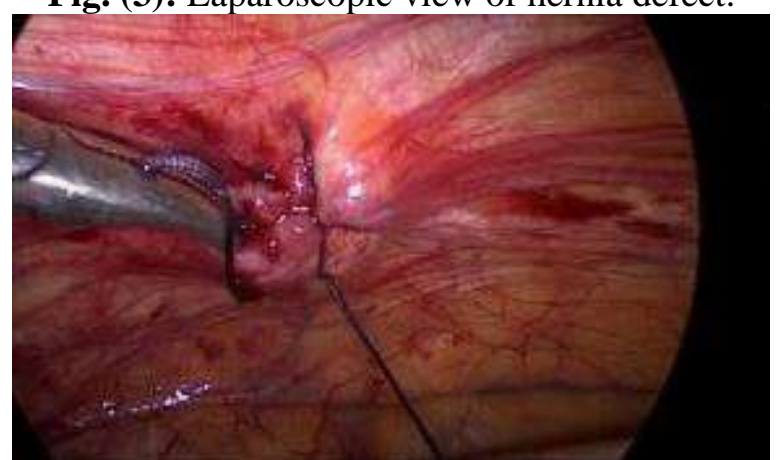

Fig. (4): Closure of hernia defect.

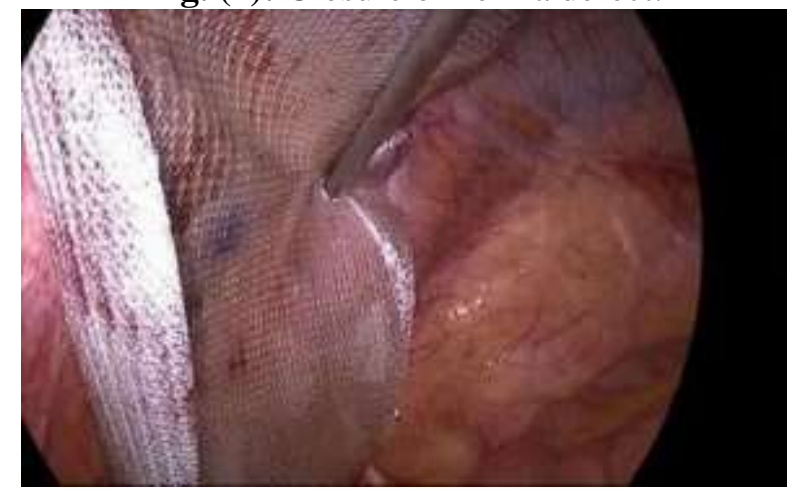

Fig. (6): Fixation of the mesh with tacks. 


\section{Statistical analysis}

The collected data were coded, processed and analyzed using the SPSS (Statistical Package for the Social Sciences) version 22 for Windows ${ }^{\circledR}$ (IBM SPSS Inc, Chicago, IL, USA). Qualitative data were represented as frequencies and relative percentages. Quantitative data were expressed as mean \pm SD (Standard deviation).

\section{RESULTS}

The age of patients ranged from 29 to 55 years and the mean age was $42.25 \pm 7.06$ and the maximum percentage age groups encountered in our study was from 40 to 50 years (18). This study included 22 male and 18 female patients. 11 male patients had incisional hernia and 11 patients with ventral hernia (Table 1).

Table (1): Age and sex distribution

\begin{tabular}{|l|c|c|}
\hline & No of patient & $\%$ \\
\hline Age groups & & \\
years: & 0 & 0 \\
$10-20$ & 2 & $5 \%$ \\
$20-30$ & 12 & $30 \%$ \\
$30-40$ & 18 & $45 \%$ \\
$40-50$ & 8 & $20 \%$ \\
$50-60$ & & \\
\hline Sex: & & \\
Male & 22 & $55 \%$ \\
Female & 18 & $45 \%$ \\
\hline
\end{tabular}

Body mass index (BMI): Mean BMI among patients was 25.43 \pm 3.66 . Most of our patients were overweight $(50 \%)$ and minority were obese (10\%) (Table 2).

Table (2) Classification of obesity according to BMI and number of patients in each group

\begin{tabular}{|l|l|c|}
\hline BMI (KG/M & $\begin{array}{l}\text { Classification } \\
\text { of obesity }\end{array}$ & $\begin{array}{c}\text { Number of } \\
\text { patients in each } \\
\text { group }(\mathbf{n}=\mathbf{4 0})\end{array}$ \\
\hline $\mathbf{1 8 . 5}$ & Underweight & 0 \\
\hline $\mathbf{1 8 . 5 - 2 4 . 9}$ & $\begin{array}{l}\text { Normal } \\
\text { weight }\end{array}$ & 16 \\
\hline $\mathbf{2 5 - 2 9 . 9}$ & Overweight & 20 \\
\hline$>\mathbf{3 0}$ & Obese & 4 \\
CLASS I: $30-$ & & 2 \\
34.9 & & 1 \\
CLASS II:35- & & 1 \\
39.9 & & 0 \\
CLASS III:>40 & & \\
CLASS & & \\
IV:>50 &
\end{tabular}

$\left(\mathrm{BMI}=\right.$ weigh $(\mathrm{Kg}) /$ Height $\left.\left(\mathrm{m}^{2}\right)\right)$

Most of our patients operated upon for LVHR were overweight (50\%) and minority were obese (10\%).
Comorbidities associated with ventral and incisional hernia: $16(40 \%)$ cases were found to have comorbidities (Table 3).

Table (3): Comorbidities associated with ventral and incisional hernia

\begin{tabular}{|l|c|c|}
\hline Comorbidities & $\begin{array}{c}\text { Number of } \\
\text { cases (n=40) }\end{array}$ & $\mathbf{\%}$ \\
\hline None & 24 & $60 \%$ \\
\hline Diabetes mellitus & 7 & $17 \%$ \\
\hline Hypertension & 5 & $13 \%$ \\
\hline $\begin{array}{l}\text { Chronic obstructive } \\
\text { lung disease }\end{array}$ & 2 & $5 \%$ \\
\hline Grade I nephropathy & 2 & $5 \%$ \\
\hline
\end{tabular}

Special habits: Among our cases, 16 cases were found to be smokers (40\%) all of them were males (Figure 7).

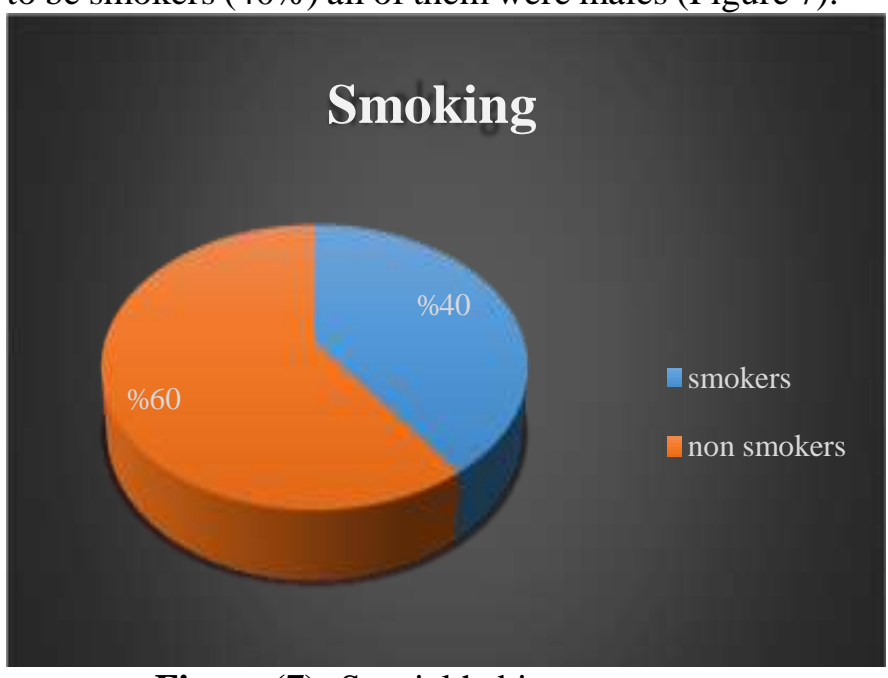

Figure (7): Special habits.

Types of previous operations: 11 of cases with previous operations were found to have midline incisions, 5 of cases with gynecological incisions and 1 with appendectomy incisions and 2 with port site incision (Table 4).

Table (4): Types of previous operations

\begin{tabular}{|l|c|c|}
\hline $\begin{array}{l}\text { Types of previous } \\
\text { operations }\end{array}$ & NO. & $\%$ \\
\hline $\begin{array}{l}\text { Midline exploratory } \\
\text { incision }\end{array}$ & 11 & $58 \%$ \\
\hline Gynecological & 5 & $26 \%$ \\
\hline Appendectomy & 1 & $5.5 \%$ \\
\hline Port site incision & 2 & $10.5 \%$ \\
\hline
\end{tabular}

Types of hernias: Twenty-one cases had virgin abdomen with no previous surgeries while 19 cases had previous surgery done before and described as follow: midline laparotomy scar (11), caesarian section scar (5), port site scar (2) and appendectomy scar (1) (Table 5).

Table (5): Types of hernias 


\begin{tabular}{|l|c|c|}
\hline \multicolumn{1}{|c|}{ Type of hernia } & NO. & \% \\
\hline $\begin{array}{l}\text { Incisional hernia following } \\
\text { laparotomies }\end{array}$ & 17 & 42 \\
\hline $\begin{array}{l}\text { Umbilical hernia and } \\
\text { paraumbilical hernia }\end{array}$ & 17 & 43 \\
\hline $\begin{array}{l}\text { Epigastric hernia } \\
\text { Port site incision following } \\
\text { laparoscopy }\end{array}$ & 2 & 10 \\
\hline
\end{tabular}

\section{Operative data (Table 6):}

1- Operative time: In first 20 operated cases the mean operative time was $120 \mathrm{~min}$ while in the last 20 cases with increasing learning, curve the operative time starts to reduce markedly and the mean time became $70 \mathrm{~min}$.

2- Defect size: The size of the defect ranged from $1 \mathrm{~cm}$ to $7 \mathrm{~cm}$ and the mean defect size was $3.22 \pm 1.15 \mathrm{~cm}^{2}$

3- Defect number: Twenty cases were found to have one defect, 13 cases were found to have two defects and 7 cases had multiple defects.

4- Conversion to open: Two cases were converted to open repair; one was due to too much extensive adhesions and the other one was due to inadvertent injury to small bowel with spillage of intestinal contents into the peritoneal cavity.

5- Intraoperative complications: One case developed port site bleeding managed laparoscopically and one case developed inadvertent bowel injury that necessitates conversion to open approach for repair of the injury.

Table (6): Descriptive of operative details

\begin{tabular}{|l|l|}
\hline Operative details & Descriptive statistics \\
\hline Mean operative time & $63.83 \pm 16.29$ minutes \\
\hline Mean defect size & $102.22 \pm 7.52 \mathrm{~cm}^{2}$ \\
\hline Conversion to open & $2(5 \%)$ \\
\hline
\end{tabular}

\section{DISCUSSION}

An increasing interest in laparoscopic surgery and the availability of new materials have encouraged the adoption of laparoscopic techniques in ventral hernia repair. Laparoscopic repair is exceedingly used and widely accepted operative procedure. General advances of laparoscopic trends are valid for patients. The short term outcome of laparoscopic repair is outstanding open repair as regard to less perioperative complications, minimal blood loss, and shorter hospital admission ${ }^{(\mathbf{1}, \mathbf{1 0})}$.

In our study $(55.0 \%)$ of the study population were males vs. $(45.0 \%)$ were females. Male gender was slightly higher than female gender, which can be explained by strenuous physical work, multiple operations in male than female and this goes with the study done by Ferrari et al. ${ }^{(11)}$ who reported in his study $17(47.3 \%)$ were female patients and $19(52.7 \%)$ were male patients; Wassenaar $\boldsymbol{e t}$ al. ${ }^{(\mathbf{1 2})}$, reported 64 female patients and 108 male patients; and Juo et al. ${ }^{(13)}$, reported $1139(31.7 \%)$ female patients and 2455 (68.3\%) male patients, in which the number of male patients exceeded that of female patients. However, it differs from the studies Basheer et al. ${ }^{(14)}$ who reported the number of female patients in his study was slightly higher than male patients [22 (55\%) patients vs. 18 (45\%) patients], due to higher cosmetic concerns of females. This goes with the studies of Andersen et al. ${ }^{(15)}$, with $30(53.6 \%)$ female patients and $26(46.4 \%)$ male patients, and Ecker et al. ${ }^{(16)}$, with 8303 (61.2\%) female patients and 5264 (38.8\%) male patients.

In our study $17 \%$ was diabetic, $13 \%$ was hypertensive and 5\% had COPD. Multiple associated conditions, such as obesity, smoking, and others, have been reported in various studies to contribute to higher recurrence rates ${ }^{(\mathbf{1 7})}$.

One of the main advantages of LVHR is less postoperative pain as compared to open approach as the wounds are minute puncture like and no much trauma of the tissues, this is proved by less requirement to analgesics in the immediate postoperative period, subjectively measured by Visual Analogue score, which was in our study $27.9 \pm 25.6$ (mild pain). This agree with Petro et al. ${ }^{(18)}$ who reported a statistical significance, regarding the postoperative pain score according to the VAS within $24 \mathrm{~h}$ postoperatively, between the two groups laparoscopic vs open $(P<0.001)$. In the laparoscopic group, it ranged from 2 to 7 , with a mean value of $4.11 \pm 1.91$, whereas in the open group, it ranged from 4 to 9 , with a mean value of $6.45 \pm 1.24$.

In our study most of our patients were discharged $2^{\text {nd }}$ or $3^{\text {rd }}$ day postoperatively and the mean hospital stay was $1.94 \pm 0.67$ days. This was in agreement with Zhang $\boldsymbol{e t}$ al. ${ }^{(19)}$ who reported that there was a significant difference between hospital stay of both groups open and laparoscopic. Only 2 patients required hospitalization for 7 days due to bowel injury and conversion to open technique. The early discharge to home decreases the incidence of hospital acquired infection from long hospital stay. Also this shorter hospital stay decreases overall cost to the hospital.

\section{CONCLUSION}

Laparoscopic ventral hernia repair is an appropriate, safe and feasible approach for ventral hernia repair with short operative time.

\section{REFERENCES}

1. Misiakos E, Patapis P, Zavras N et al. (2015): Current trends in laparoscopic ventral hernia repair. JSLS, 
19(3):2015.00048. https://pubmed.ncbi. nlm.nih.gov/ 26273186/

2. Luijendijk R, Hop W, Van den Tol M et al. (2000): A comparison of suture repair with mesh repair for incisional hernia. N Eng J Med., 343:392-398.

3. Shell D, de la Torre J, Andrades P et al. (2008): Open repair of ventral incisional hernias. Surg Clin North Am., 88(1): 61-83.

4. Leblanc K, Booth W (1993): Laparoscopic repair of incisional abdominal hernias using polytetrafluoroethylene: preliminary findings. Surg Laparosc Endosc., 3:39-41.

5. Stoppa R (1989): The treatment of complicated groin and incisional hernias. World J Surg., 13(5):545-54.

6. Rives J, Pire J, Flament J et al. (1985): Treatment of large eventrations: new therapeutic indications apropos of 322 cases. Chirurgie, 111:215-225.

7. Wantz G (1991): Incisional hernioplasty with Mersilene. Surg Gynecol Obstetr., 172:129-137.

8. Eker H, Hansson B, Buunen M et al. (2013): Laparoscopic vs open incisional hernia repair: a randomized clinical trial FREE. JAMA Surg., 148:259263.

9. Kumar D, Khan H, Qureshi M (2015): Outcome of four years experience in laparoscopic ventral hernia repair. Pak J Med Sci., 31(4):987-990.

10. Olmi S, Scaini A, Cesana G et al. (2007): Laparoscopic versus open incisional hernia repair. Surg Endosc., 21: 555-559.

11. Ferrari G, Miranda A, Sansonna F et al. (2008): Laparoscopic management of incisional hernias $>15 \mathrm{~cm}$ in diameter. Hernia, 12: 571-576.
12. Wassenaar E, Schoenmaeckers E, Raymakers J et al. (2010): Mesh-fixation method and pain and quality of life after laparoscopic ventral or incisional hernia repair; a randomized trial of three fixation techniques. Surg Endosc., 24:1296-1302.

13. Juo Y, Skancke M, Holzmacher J et al. (2017): Laparoscopic versus open ventral hernia repair in patients with chronic liver disease. Surg Endosc., 31(2):769-777.

14. Basheer M, Negm A, El-Ghadban H et al. (2018): Laparoscopic versus open ventral hernia repair: a comparative study. Egypt J Surg., 37:465-71.

15. Andersen L, Klein M, Gögenur I et al. (2009): Longterm recurrence and complication rates after incisional hernia repair with the open onlay technique. BMC Surg., 9:6-11.

16. Ecker B, Kuo L, Simmons K et al. (2016): Laprascopic versus open ventral hernia repair: longitudinal outcomes and cost analysis using statewide claims data. Surg Endosc., 30(3):906-15

17. Bencini L, Sanchez L, Bernini M et al. (2009): Predictors of recurrence after laparoscopic ventral hernia repair. Surg Laparosc Endosc Percutan Tech., 19(2):128 132.

18. Petro C, Como J, Yee $S$ et al. (2015): Posterior component separation and transverses abdominis muscle release for complex incisional hernia repair in patients with a history of an open abdomen. J Trauma Acute Care Surg., 78:422-429.

19. Zhang V, Zhou H, Chai Y et al. (2014): Laparoscopic versus open incisional and ventral hernia repair: a systematic review and metaanalysis. World J Surg., 38:2233-2240. 